\title{
Splicing Inhibitor H3B-8800
}

National Cancer Institute

\section{Source}

National Cancer Institute. Splicing Inhibitor H3B-8800. NCI Thesaurus. Code C129546.

An orally bioavailable inhibitor of the splicing factor 3B subunit 1 (SF3B1), with potential antineoplastic activity. Upon administration, H3B-8800 binds to and blocks the activity of SF3B1, a core spliceosome protein that is mutated in various cancer cells. This modulates RNA splicing by preventing aberrant mRNA splicing by the spliceosome, blocks RNA missplicing, enhances proper RNA splicing and prevents the expression of certain tumorassociated genes. This leads to an induction of apoptosis and prevents tumor cell proliferation. In many cancer cells, core spliceosome proteins, including SF3B1, U2 small nuclear ribonucleoprotein auxiliary factor 1 (U2AF1), serine/arg inine-rich splicing factor 2 (SRSF2) and U2 small nuclear ribonucleoprotein auxiliary factor subunit-related protein 2 (ZRSR2), are mutated and aberrantly activated leading to a dysregulation of mRNA splicing. 